\title{
Circulação de crianças e adolescentes na rede tecida pelo Programa de Erradicação do Trabalho Infantil (PETI)
}

\section{Circulation of children and adolescents in network by the Program for the Eradication of Child Labour (PETI)}

\section{Circulación de niños y adolescentes en la red tejida por el Programa de Erradicación del Trabajo I nfantil (PETI)}

\section{I rme Salete Bonamigo*}

Universidade Comunitária da Região de Chapecó - Unochapecó, Chapecó, Santa Catarina, Brasil

\section{Celso Francisco Tondin**}

Universidade Comunitária da Região de Chapecó - Unochapecó, Chapecó, Santa Catarina, Brasil

\section{Misael Szytko***}

Universidade Comunitária da Região de Chapecó - Unochapecó, Chapecó, Santa Catarina, Brasil

\section{Eduarda Moro****}

Universidade Comunitária da Região de Chapecó - Unochapecó, Chapecó, Santa Catarina, Brasil

\section{Tiago Ramos*****}

Universidade Comunitária da Região de Chapecó - Unochapecó, Chapecó, Santa Catarina, Brasil

\section{Giovane Biazi******}

Universidade Comunitária da Região de Chapecó - Unochapecó, Chapecó, Santa Catarina, Brasil

\footnotetext{
RESUMO

O Programa de Erradicação do Trabalho Infantil (PETI) é uma política social que visa proteger crianças e adolescentes, de sete a 15 anos, e contribuir para o seu desenvolvimento integral. Este artigo discute as implicações do PETI no cotidiano de crianças, adolescentes e suas famílias, com base em pesquisa realizada em Chapecó (SC) no ano de 2013. As informações foram produzidas por meio de acompanhamento das atividades desenvolvidas no programa e realização de entrevistas com três crianças, uma adolescente, suas famílias e profissionais. Foi utilizada a Teoria Ator-Rede como dispositivo teórico-metodológico para o desenvolvimento do estudo, cujos
} 
resultados indicam a importância do PETI para os participantes pela possibilidade de convivência em espaço considerado seguro, com atividades que contribuem para o desenvolvimento social, afetivo e pedagógico. No entanto, o programa não garante a participação integral das crianças e adolescentes em situação de trabalho infantil, pois elas deixam de frequentá-lo quando precisam auxiliar seus responsáveis em tarefas no âmbito familiar. Analisa-se que a rede que vem sendo tecida ainda não possibilita uma transformação efetiva quanto à erradicação do trabalho infantil, necessitando da conexão de outros atores para que os pais possam ao mesmo tempo trabalhar, ter a casa cuidada e seus filhos protegidos.

Palavras-chave: trabalho infantil, teoria ator-rede, PETI, políticas sociais.

\section{ABSTRACT}

The Program for the Eradication of Child Labour (PETI) is a social policy that aims to protect children and adolescents from seven to 15 years, and contribute to their integral development. This article discusses the implications of PETI in daily life of children, adolescents and their families, based on research conducted in Chapecó (SC) in 2013. Data were produced by means of monitoring the activities in the program and interviews with three children, an adolescent, their families and professionals. The ActorNetwork Theory was used as theoretical- methodological device for the development of the study, whose results indicate the importance of PETI to the participants due to the possibility of coexistence in space considered safe, with activities that contribute to the social, emotional and educational development. However, the program does not guarantee the full participation of children and adolescents in situations of child labor, because they fail to attend it when they need help in their responsible tasks within the family. It analyzes the network that has been woven not possible an effective transformation as to eradication of child labor, requiring the connection of other actors so that parents can work, be cared home and your kids safe.

Keywords: child labor, actor-network theory, PETI, social policies.

\section{RESÚMEN}

El Programa de Erradicación del Trabajo Infantil (PETI) es una política social que visa proteger niños y adolescentes, de siete a quince años, y contribuir para su desarrollo integral. Basado en investigación realizada en Chapecó (SC) en el año 2013, este artículo discute las implicaciones del programa PETI en la vida cotidiana de niños, adolescentes y sus familias. Las informaciones fueron producidas por medio de acompañamiento de las actividades desarrolladas en el programa y realización de entrevistas con tres niños, una adolescente, sus familias y profesionales. La teoría del actorred fue utilizada como orientación teórico metodológico para el desarrollo del estudio, cuyos resultados muestran la importancia del PETI a los participantes por la posibilidad de convivencia en espacio por ellos considerado seguro y con actividades que contribuyen al desarrollo social, afectivo y educativo. Sin embargo, el programa no garantiza la participación integral de los niños y adolescentes en situación de trabajo infantil, pues ellos dejan de frecuentarlo cuando necesitan auxiliar sus responsables en tareas en el ámbito familiar. La analise apunta que la red que viene siendo tejida todavía no permite una transformación efectiva en relación a la erradicación del trabajo infantil, necesitando de la conexión de otros actores para que los padres puedan trabajar, tener el hogar cuidado y sus hijos protegidos.

Palabras clave: trabajo infantil, teoría actor-red, PETI, políticas sociales. 


\section{Introdução}

As políticas sociais podem ser compreendidas como redes sociotécnicas, no sentido atribuído por Latour (2001) de serem resultados de associações entre múltiplos atores, humanos e não humanos, que dispõem de diferentes interesses, estratégias e recursos para o estabelecimento e desenvolvimento de projetos, programas e serviços. Essas associações abrangem vinculações entre atores estatais e não estatais em diferentes escalas: local, regional, nacional e internacional. Conceber políticas sociais como redes significa defini-las como efeito de processos de composições e associações que lhes conferem formas sempre provisórias, com contornos variáveis e propriedades sempre resultantes das interações em curso.

O objetivo deste artigo é discutir o Programa de Erradicação do Trabalho Infantil (PETI), a partir do acompanhamento de crianças e adolescentes que dele participam para conhecer como a rede é tecida e como os seus atores constroem e explicam o mundo relacionado ao trabalho infantil e à participação no PETI.

A Constituição Federal de 1988 estabeleceu os direitos de cidadania e decorrente disso foram sendo implantados diversos sistemas de atendimento em políticas sociais que visam à garantia, por meio de programas e ações, dos direitos sociais. Portanto, é nesse momento que a assistência social é elevada à condição de política pública, "constituindo, no mesmo nível da saúde e previdência social, o tripé da seguridade social que ainda se encontra em construção no país" (Ministério do Desenvolvimento Social e Combate à Fome, 2009, p. 4).

Em seguida, foi promulgada, no ano de 1993, a Lei Orgânica da Assistência Social - LOAS, que prevê, em seu artigo 1o, que ela "é Política de Seguridade Social não contributiva, que provê os mínimos sociais, realizada através de um conjunto integrado de ações de iniciativa pública e da sociedade, para garantir o atendimento às necessidades básicas" (Brasil, 1993). A partir daí os governos se empenharam, embora em grau de comprometimento bem diferentes, em estabelecer uma rede de proteção e promoção social, cujo marco maior é a criação do Sistema Único de Assistência Social - SUAS, em 2005, conforme determinações da LOAS e da Política Nacional de Assistência Social, de 2004. Em 2011 o SUAS se tornou política de Estado, por meio da Lei no 12.435, de 6 de julho.

Nessa trajetória, destacamos o Programa de Erradicação do Trabalho Infantil - PETI, criado em 1996, e que em 2005 foi integrado, por meio da Portaria GM/MDS no 666, de 28 de dezembro, com o Programa Bolsa Família, que havia sido criado pela Lei № 10.836, de 
9 de janeiro de 2004, permitindo a ambos que suas especificidades fossem mantidas. "Dessa forma, ao mesmo tempo, os dois Programas agem em sinergia, no que se refere aos objetivos de combater a pobreza e de erradicar o trabalho de crianças e adolescentes" (Ministério do Desenvolvimento Social e Combate à Fome, 2010a, p. 44).

Assim, a importância de análises das políticas públicas na atualidade é evidente para o Estado brasileiro, governos, sociedade e meio acadêmico, visto que a "Constituição Cidadã" completou 25 anos em 2013 e, no caso da Assistência Social, a LOAS completou 20 anos, um período que permite certo olhar sobre os efeitos das políticas sociais na sociedade brasileira. Especificamente em relação ao PETI, o Ministério do Desenvolvimento Social e Combate à Fome - MDS promoveu, entre outubro e dezembro de 2008, dois estudos nacionais: Pesquisa Quantitativa de Avaliação do Programa de Erradicação do Trabalho Infantil - PETI (Fundação Euclides da Cunha; Ministério do Desenvolvimento Social e Combate à Fome, 2009) e Estudo Qualitativo para Avaliação do Programa de Erradicação do Trabalho Infantil - PETI (Herkenhoff \& Prates; Ministério do Desenvolvimento Social e Combate à Fome, 2009), cujos resultados demonstraram a contribuição do Programa para o combate ao trabalho infantil no país.

Cabe assim ao meio acadêmico promover outros estudos, relacionados às realidades locais e regionais, que possam contribuir com a problematização desse importante programa de proteção social de crianças, adolescentes e suas famílias, no sentido de potencializar sua ação transformadora da realidade social e promover reflexões que possam fazer frente aos desafios que ainda se apresentam. Compreende-se que em uma análise de determinada política pública torna-se importante "dar sentido e entendimento ao caráter errático da ação pública [...] é caracterizada por incoerências, ambigüidades e incertezas em todos os estágios e em todos os momentos" (Arretche, 1998, p. 30).

Tendo em vista esse cenário, 0 presente estudo caracteriza-se como uma forma de análise do PETI em sua especificidade na cidade de Chapecó (SC), com base em pesquisa realizada durante o ano de 2013, cujo objetivo foi analisar as implicações do PETI no cotidiano de crianças, adolescentes que dele participam e suas famílias.

\section{Método}

Fundamentos Teórico-Metodológicos

O estudo utilizou os fundamentos teórico-metodológicos da Teoria Ator-Rede (TAR), o que permite seguir a construção e a fabricação 
dos fatos e acompanhar atores sem impor-lhes uma definição anterior. Esta abordagem tornou possível a descrição de associações heterogêneas e os mecanismos de sua consolidação ou transformação, não reduzindo seus efeitos nem a um ator, nem a uma rede, mas a composição de ambos (Latour, 2006). Segundo Latour (2001), rede é uma estrutura composta de elementos em interação, marcada por uma forte heterogeneidade e permite evidenciar o hibridismo presente nas associações que se configuram: mistura entre humanos e não humanos, sujeitos e objetos, natureza e cultura. O termo ator é utilizado para nomear qualquer pessoa, instituição ou coisa que tenha agência, que produza algum efeito na rede e a expressão "não-humano" para designar objetos: equipamentos, materiais, dispositivos tecnológicos, dentre outros. Os não humanos na Teoria Ator-Rede não são considerados passivos, nem submetidos às ações humanas, mas atores que produzem efeitos na rede onde estão vinculados.

Para Andrade (2006, p. 64), a Teoria Ator-Rede torna-se um importante dispositivo para "analisar a formação de políticas públicas, pois ao tratar conjuntamente o processo do organizar em suas características estruturais e relacionais esta abordagem propicia uma maior compreensão da gestão como uma realização coletiva que integra diferentes atores". Desse modo, o PETI foi concebido como uma rede em construção, na qual diferentes atores articulam associações para a sua existência e seu funcionamento.

Um estudo ator-rede demanda a presença constante e duradoura do pesquisador no campo, seguindo os atores em seu cotidiano para descrever o modo como eles compõem e estabilizam redes, como eles constroem e explicam o mundo.

Procedimentos Metodológicos

A pesquisa foi realizada a partir do acompanhamento da circulação de atores na rede tecida pelo PETI. A entrada na rede aconteceu a partir da escolha e acompanhamento de quatro participantes de duas Unidades de Atendimento Sócio Educativo (UASEs), onde funciona atualmente o PETI: três crianças (Teresa Joana e Pedro) e uma adolescente (Maria), de 10 a 13 anos de idade, conforme descrição no quadro 1. Os nomes são fictícios. O critério de escolha para seleção das crianças e adolescentes foi de suspeita ou confirmação de encontrar-se em situação de trabalho infantil. As UASES localizam-se em duas diferentes regiões de Chapecó.

\section{Quadro 1 - Crianças/ adolescentes participantes da pesquisa Crianças/ adolesc Sex I dad Situação de trabalho infantil entes}




\begin{tabular}{llll}
\hline (nomes fictícios) & & & \\
\hline Teresa (UASE I) & F & 10 & $\begin{array}{l}\text { Serviços domésticos e cuidados com o } \\
\text { irmão bebê }\end{array}$ \\
Joana (UASE I) & F & 11 & $\begin{array}{l}\text { Serviços domésticos e cuidados com o } \\
\text { pai alcoolista } \\
\text { Ptividades em um circo (período de } \\
\text { dois meses) }\end{array}$ \\
Maria (UASE II) & F & 13 & \begin{tabular}{l} 
Cuidados com o irmão mais novo \\
\hline
\end{tabular}
\end{tabular}

Fonte: elaborado pelos autores (2014).

Além do acompanhamento de atividades no PETI e realização de entrevistas com as três crianças e a adolescente, foram realizadas também entrevistas com: as suas famílias (quatro); monitores das UASES (três); coordenadores das UASES (dois); professores das escolas onde as crianças estudavam (três); coordenadoras pedagógicas (duas) e diretora (uma) das escolas onde as crianças estudavam; gestora (uma); E assistente social do Centro de Referência de Assistência Social (CRAS) de uma das regiões onde se situa uma das UASES.

Para o conhecimento da rede e seu funcionamento, os pesquisadores (três estudantes do Curso de Psicologia da Unochapecó e um mestrando do Mestrado em Polícias Sociais e Dinâmicas Culturais, dois em cada UASE), coautores deste artigo, acompanharam alguns momentos do cotidiano das UASES por meio de observação de atividades, conversas informais com participantes destas, diálogos com monitores e coordenadora das UASES e visitas às famílias. Para a realização das observações e entrevistas, foram respeitados os princípios éticos e solicitado aos participantes da pesquisa 0 consentimento livre e esclarecidos; para as criança/adolescentes foi solicitado assentimento e também consentimento livre e esclarecido aos pais. A pesquisa foi aprovada pelo Comitê de Ética em Pesquisa CEP da Unochapecó (Registro no CEP - no 285/12).

\section{A Rede de atores tecida pelo PETI}

O PETI é um Programa de âmbito nacional, de natureza intergovernamental e intersetorial, e que articula as três esferas de governo no sentido da integração de um conjunto de organizações governamentais e não governamentais em prol da realização de iniciativas, estratégias e ações com o objetivo de contribuir para a erradicação do trabalho infantil no Brasil, ou seja, o PETI visa

"proteger e retirar crianças e adolescentes com idade inferior a 16 anos da prática do trabalho precoce, resguardado o trabalho 
na condição de aprendiz a partir de 14 anos, em conformidade com o que estabelece a Lei de Aprendizagem (10.097/2000)" (Ministério do Desenvolvimento Social e Combate à Fome, 2010b, p. 40).

O redesenho do PETI indica que ele passa, em 2005, a estar integrado com o Programa Bolsa Família. No âmbito do MDS, o PETI compõe o SUAS com duas ações articuladas: o Serviço de Convivência e Fortalecimento de Vínculos (SCFV), como serviço socioeducativo; e a transferência condicionada de renda direta às famílias com crianças e adolescentes retiradas da situação de trabalho. Essa integração foi motivada pelas ideias de universalização do acesso, enfrentamento da duplicidade de benefícios, transferência de renda pelo cartão e maior transparência na gestão do PETI.

A partir de deliberação da VI Conferência Nacional de Assistência Social, ocorrida em 2007, o Conselho Nacional de Assistência Social (CNAS) aprovou, por meio da Resolução no 109, de 11 de novembro de 2009, a Tipificação Nacional dos Serviços Socioassistenciais, "na qual se traduz a concepção de que o enfrentamento ao trabalho infantil, na política de Assistência Social, dar-se-á, também, por meio de Serviços de Proteção Social Básica e Proteção Social Especial, desenvolvidos de forma articulada entre si" (Ministério do Desenvolvimento Social e Combate à Fome, 2010b, p. 53). Isso se traduz no fortalecimento da ideia de que o PETI, com a integração com o PBF, além da transferência de renda às famílias, possibilita assegurar:

1) a inclusão das crianças e adolescentes em situação de trabalho infantil no SCFV; 2) o aprimoramento do processo de identificação das situações de trabalho infantil, nos espaços públicos, por meio do Serviço Especializado em Abordagem Social; 3) a orientação e o acompanhamento das famílias por meio do Serviço de Proteção e Atendimento Especializado a Famílias e Indivíduos (PAEFI) e do Serviço de Proteção e Atendimento Integral à Família (PAIF), por referenciamento e contrarreferenciamento dos usuários no Sistema, conforme especificidades das situações vivenciadas, dentro da perspectiva do trabalho em rede concebido pelo SUAS. (Ministério do Desenvolvimento Social e Combate à Fome, 2010, p. 53-54).

Dessa maneira, o SCFV, como tipificado na Proteção Social Básica, incorporou as ações socioeducativas e de convivência como preveem as normativas do PETI, o que requer dizer que se destina a crianças e adolescentes de seis a 15 anos, com vistas a "assegurar, prioritariamente, a inclusão e a permanência de crianças e adolescentes identificados em situação de trabalho, observando a 
condicionalidade de frequência prevista na normativa". (Ministério do Desenvolvimento Social e Combate à Fome, 2010b, p. 54).

\subsection{O PETI em Chapecó (SC)}

O Programa de Erradicação do Trabalho Infantil (PETI) é implementado de forma articulada pelo Ministério do Desenvolvimento Social e Combate à Fome (MDS) e pela esfera municipal. No caso de Chapecó, pela Secretaria Municipal de Assistência Social (SEASC).

Com o seu redesenho, em Chapecó, o PETI passa a funcionar junto às Unidades de Atendimento Sócio Educativo (UASEs), que são espaços de convivência e formação que disponibilizam atividades socioeducativas às crianças e adolescentes no contraturno escolar. Atendem crianças e adolescentes de seis a 14 anos, dentre elas, as beneficiadas pelo PETI e PBF, que Ihes são encaminhadas pelo Centro de Referência de Assistência Social (CRAS). Quando necessário, as UASES fazem encaminhamentos relacionados às crianças, adolescentes e suas famílias a outros órgãos, programas e serviços do município.

No município, há nove unidades que atendem a faixa etária de seis a 14 anos, das quais duas localizam-se em aldeias indígenas. Além destas, ainda há quatro unidades destinadas a qualificar adolescentes de 14 a 18 para o mercado de trabalho: três nomeadas de ArteJ ovem e uma de Posto Pequeno Lavador.

\subsection{Entrada das crianças e da adolescente na rede tecida pelo PETI}

Nas situações pesquisadas, a entrada na rede de Pedro e Maria se deu por meio de encaminhamento do CRAS à UASE, no momento em que suas famílias passaram a receber a Bolsa Família, como uma condição, já que "As ações socioeducativas e de convivência [...] devem ser frequentadas pelas crianças/adolescentes das famílias oriundas do PETI, assim como pelas famílias beneficiárias do PBF que apresentarem situação de trabalho infantil" (Rua, 2007, p. 24).

A entrada na rede de Teresa e Joana aconteceu pela procura espontânea da família, pois as UASEs não se limitam ao atendimento das crianças e adolescentes vinculadas ao PETI e ao PBF. Teresa frequenta o PETI a cerca de um ano e meio, juntamente com seu irmão. A família de Teresa teve conhecimento do programa por meio de alguns vizinhos. Assim, a mãe Teresa foi ao programa verificar o que precisaria fazer para que alguns de seus filhos começassem a participar. A coordenadora da unidade encaminhou a mãe ao Centro de Referência de Assistência Social (CRAS) do bairro e após os filhos começaram a participar do programa. A família não recebe benefício do PBF ou PETI, pois não atende alguns dos requisitos exigidos. A 
mãe explicou que o motivo da filha participar do PETI está relacionado às questões de segurança e lazer, pois segundo ela, "a importância é que eles não tão na rua, principalmente a Teresa que é menina, mais frágil. E é um lugar que eles estão seguros, aprendendo mais também, porque além do colégio é uma ajuda para estudos que eles ganham lá".

Joana participa do PETI há aproximadamente três anos. A avó de Joana ficou sabendo a respeito do projeto através de vizinhos e das agentes comunitárias de saúde da Unidade Básica de Saúde (UBS) do bairro. Assim, a avó foi até ao PETI e foi encaminhada pela coordenadora ao CRAS e, posteriormente, começou a receber o benefício do PBF. Além da condição do benefício, a participação de Joana estava ligada às questões da segurança e atividades educacionais. Segundo relato da avó, o PETI é importante não apenas na vida de Joana, como nas demais crianças, pois

“as crianças ao invés de estar na rua estão lá e eles são bem recebidos, bem alimentados. Tem criança que não tem nem o que comer em casa, [...] lá eles têm ensinamento, tem física, acho que tem tudo lá". (Avó de Joana)

Nas UASEs pesquisadas, portanto, nem todas as crianças e adolescentes encontram-se em situação de trabalho infantil e não é feita nenhuma distinção entre as crianças vinculadas ao PETI, ao PBF e as outras crianças do bairro. Teresa e Joana frequentam a Unidade I, que atende aproximadamente 42 crianças e adolescentes, 24 no período matutino e 18 no período vespertino. Atuam na Unidade três monitores, um professor de educação física, uma pedagoga/coordenadora da unidade e outra pedagoga que trabalha apenas dois dias por semana. São realizadas atividades como: oficinas, gincanas, recreação, atletismo, artesanato, leitura, cálculos e escrita e atividades de reforço escolar.

A estrutura física desta unidade é pequena, mas as atividades também são realizadas no espaço de um complexo esportivo, que conta com um ginásio, um campo de futebol, uma pista de skate e uma quadra de vôlei. Essa estrutura contribui para que o professor tenha liberdade na hora de realizar atividades com as crianças.

Maria e Pedro frequentam a Unidade II, que atende aproximadamente 60 crianças e adolescentes. O espaço físico é pequeno e considerado provisório, pois se está buscando outro local para o seu funcionamento. Entre as atividades que oferecem, estão as oficinas de esporte, de dança, de judô e acompanhamento das tarefas escolares. Trabalham nesta Unidade dois monitores e a coordenação.

3.3. Articulações e desarticulações na rede 
A entrada das crianças e da adolescente nas UASEs colocam em evidência alguns atores da rede vinculada ao PETI: o PBF, o CRAS e a UBS. O CRAS constitui-se a porta de entrada para as UASEs, já que é este órgão que faz o encaminhamento das crianças e adolescentes às UASEs, seja quando a busca é voluntária pela família seja quando é pela indicação de outros programas/serviços/órgãos. Cabe ao CRAS o papel de averiguar qualquer denúncia sobre trabalho infantil que receber. As UBS atuam em conjunto com as UASEs e CRAS por meio de encaminhamentos e troca de informações diversas.

Os profissionais da escola entrevistados relatam desconhecimento e distanciamento desta instituição em relação ao PETI/UASE. Alguns, especialmente aqueles que trabalham em sala de aula (professores), sequer sabem que as crianças e a adolescente participantes da pesquisa frequentam o referido equipamento público. Nesse sentido, uma professora afirma: "Não sabia que ele frequentava o PETI. A gente não conhece o PETI, alguém de lá nunca veio aqui e não tem esse entrosamento, essa ligação com a escola".

Por outro lado, uma professora, a diretora e os coordenadores pedagógicos entrevistados disseram que sabem sobre esta participação, porém desconhecem o funcionamento e atividades realizadas pela UASE e o desenvolvimento dos seus alunos neste espaço, como dito pela diretora entrevistada: "Existe pouco contato da escola com o PETI, pela correria. A escola entra mais em contato com o PETI quando precisam de um número de telefone de uma família por exemplo. O PETI seria um meio de contato para saber informações".

Os profissionais das UASEs e do CRAS entrevistados avaliam o trabalho desenvolvido pelo PETI, ressaltando a importância para a retirada das crianças do espaço da rua e a oferta de um espaço de convivência e sociabilidade. No entanto, referem a necessidade de melhoria na gestão e na estrutura das UASEs:

“O que percebo que precisa ser melhorado é essa questão de ter mais reuniões, capacitações, uma maior integração de todos os coordenadores, dos professores, os CRAS, para uma troca de experiências de todos os PETIs [...]. Outro ponto negativo é a falta de estrutura das unidades". (Profissional UASE).

Por sua vez, a gestora entrevistada reforça o papel da UASE na retirada das crianças da rua e do trabalho infantil com um ganho social importante para a cidade, especialmente no centro da cidade:

“Anos atrás, a gente percebia a existência e perambulação de crianças engraxando, vendendo picolé, algodão doce [...], especialmente no centro. Hoje a gente já consegue não 
visualizar mais [essas situações]. Hoje, a gente percebe as crianças em sala de aula, estudando". (Gestora UASE).

Além dos atores evidenciados pela pesquisa, as orientações técnicas do MDS referentes ao PETI dão visibilidade a outros atores que poderiam produzir efeitos na rede pesquisada:

O PETI necessita de ampla articulação intersetorial, ou seja, uma ação coletiva, compartilhada e integrada com diversas políticas públicas - especialmente com as políticas de educação, saúde, esporte, cultura, agricultura, trabalho, direitos humanos, entre outras - e órgãos de defesa de direitos - Ministério Público, Conselhos Tutelares, entre outros -, tendo como horizonte a garantia do atendimento e a integralidade dos direitos de crianças e adolescentes em situação de trabalho e suas famílias. (Ministério do Desenvolvimento Social e Combate à Fome, 2010, p. 71 e 72).

A partir da TAR, é possível pensar no rastreamento de relações e atores que poderiam fortalecer a rede, tendo em vista o cumprimento de seu papel de proteção social às crianças e aos adolescentes em situação de trabalho infantil. A noção de rede dá visibilidade à provisoriedade dos fluxos, na qual sempre elementos podem ser articulados e desarticulados, cursos podem ser estabilizados e desestabilizados para que produzam vínculos e efeitos interessantes à participação das crianças, adolescentes e suas famílias. A TAR "'sustenta ser possível rastrear relações mais sólidas e descobrir padrões mais reveladores quando se encontra um meio de registrar os vínculos entre quadros de referência instáveis e mutáveis, em vez de tentar estabilizar um deles." (Latour, 2012, p. 45).

\subsection{As situações de trabalho infantil}

Conforme apresentado no quadro 1 , as três crianças e uma adolescente, três do sexo feminino e uma do masculino com idades de 10 a 13 anos, executam de alguma forma o "trabalho infantil". Além dos serviços da casa, Teresa cuida do irmão bebê, Joana cuida do pai alcoolista e Maria toma conta do irmão mais novo. Nestes três casos ocorre o que é descrito e classificado como "trabalho infantil no âmbito familiar", abrangendo "situações em que a criança e o adolescente com idade inferior a 16 anos trabalha diretamente com os pais ou parentes, e em função ou a favor deles, seja na própria residência, seja em outro local." (Medeiros Neto \& Marques, 2013, p. 8).

Sobre as tarefas no âmbito familiar, Maria afirma: "Eu ajudava a lavar a louça, arrumar as camas, passar pano". Por sua vez, sua mãe descreve as tarefas que a adolescente desempenha: 
“Hoje ela ajuda em casa como lavar louça, varrer a casa, arrumar a cama, lavar o banheiro. Quando toma banho, ela limpa o banheiro, que tem que secar, essas coisas simples, que não é coisa pesada, como arrumar o sofá, brincar com a nenê. As coisas pesadas eu que faço." (Maria).

No entanto, a professora de Maria relata que "Às vezes, a Maria falta para ficar cuidando da irmã. Ao invés da filha mais velha cuidar, quem falta é a Maria".

No caso de Joana, ela realiza serviços domésticos, tanto em sua casa quanto em uma residência em que a avó trabalha como diarista, que a leva junto para auxiliá-la na limpeza. A respeito das situações de trabalho doméstico a avó pondera que

“acho que limpar a casa não é errado, porque eu acho assim que ela vai querer aprender alguma coisa, porque hoje diz que é proibido as crianças trabalharem fora, mas ela não trabalha fora, ela trabalha aqui, ela limpa aqui". (Joana).

Joana também cuida do pai alcoolista, no sentido de que "dá remédio, se precisa pega a roupa dele e ajeita [...], se precisa ela leva para consulta, é uma menina esperta, ela é bem responsável pelo pai" (Avó de Joana). Sobre esse cuidado Joana descreve o seguinte: "Eu ficava fazendo o serviço e de olho nele, porque não podia deixar ele sair, se ele fosse sair eu ligava pra mãe".

Teresa ajuda a cuidar de seu irmão bebê e realiza tarefas de limpeza da casa. Sua mãe assim se refere a essa situação:

"eu trabalho e aí minha outra filha [mais velha] não dá conta do neném e do serviço da casa, e aí a Teresa tem que ficar em casa e ajudar ela [...]. E às vezes não dá tempo de fazer o serviço até na hora de ir no PETI, aí a Teresa tem que faltar pra ajudar em casa". (Teresa).

A mãe diz ainda: "é auxiliar, lavar a louça, ajeitar a roupa, limpar a casa, dar uma organizada na casa". Teresa assim descreve as suas atividades: "ajudo a lavar a louça, lavar o carro, arrumar o quarto e cuidar do meu irmãozinho".

As situações de trabalho infantil levantadas pela pesquisa colocam em evidência a situação de precariedade socioeconômica das famílias que precisam recorrer ao auxílio dos filhos para a organização da vida doméstica familiar como uma forma de liberar os pais e irmãos para o trabalho e também aliviar a sobrecarga de atividades que estes realizam em casa e fora dela. Também dá visibilidade à falta de equipamentos públicos necessários para que a família consiga trabalhar e ao mesmo tempo garantir a proteção dos filhos como, por 
exemplo, a oferta insuficiente de vagas em centros de educação infantil para crianças de zero a três anos; e não acesso das famílias a equipamentos existentes como, por exemplo, o Centro de Atenção Psicossocial de Álcool e outras Drogas (CAPS AD).

Também, mostra que ainda é tênue a separação entre as situações de aprendizagem sociocultural e a situação de trabalho infantil. A criança e o adolescente, no processo de socioeducação, aprendem, com a mediação dos adultos, práticas, dentre outras, de cuidado do lar e da família, o que é uma condição para a inserção deles na cultura que partilham. Porém, no caso dos participantes da pesquisa, esta aprendizagem excede o caráter educativo a ponto de tomar o lugar de outras aprendizagens e exigir um tempo e uma dedicação que resultam em prejuízo ora na frequência escolar ora na frequência à UASE. A pesquisa de Herkenhoff \& Prates e MDS (2010) identifica que o trabalho infantil no âmbito familiar é existente na vida de quase todas as crianças e adolescentes participantes do PETI.

No caso do menino Pedro, houve o envolvimento em atividades de circo, por um período de dois meses, para as quais recebia 30 reais por mês. Esta é classificada como atividade no âmbito artístico, definida como: "toda e qualquer relação de trabalho cuja prestação de serviços ocorre por meio de expressões artísticas variadas, por exemplo, no campo do teatro, da televisão, do cinema, do circo e do rádio" (Medeiros Neto \& Marques, 2013, p. 36). A atividade foi assim referida pela criança:

"malabarismos, rolo e corda [...]. No malabarismo, joga três bolinhas para cima, sem deixar cair no chão; o rolo é uma tábua com uma bola embaixo e ele tem que se equilibrar em cima da bola; a corda, ele tem que caminhar em cima da corda e se equilibrar." (Pedro).

3.5. Deslocamentos provocados pela rede do PETI na vida das crianças e adolescentes

Considerando que a rede é uma estrutura de interconexão aberta, instável e provisória e que cada novo vínculo provoca modificações nas linhas conectadas e imprimem novas direções, cabe perguntar: que deslocamentos a rede que compõe o PETI provocou na vida das crianças e da adolescente? É importante ressaltar que o ator vinculado à rede "não age simplesmente. Ele é levado a agir tendo em vista a rede de relações em que está envolvido, sem ser agido por ela" (Arendt, 2007, p. 281, grifo do autor).

A entrada das crianças e adolescente na rede do PETI possibilitou o acesso deles às atividades socioeducativas e a convivência com outras crianças, adolescentes e monitores. Maria afirma gostar das oficinas de dança, esporte e judô; quanto ao esporte, gosta de jogar 
futebol, vôlei e basquete. Diz que na UASE conheceu pessoas diferentes, professores legais e tem mais amigas, quando está lá sente-se alegre. Pedro avalia que o PETI é bom porque ele fez novos amigos e os professores são legais. Sua mãe ressalta que ele gosta de jogar futebol, vôlei e basquete: "ele gosta [...] de jogar bola, ele não gosta muito de escrever, mas gosta mais de jogar bola".

A mãe de Teresa afirma que ela gosta de ir ao PETI porque lá "eles cuidam muito bem das crianças, lá eles comem bem, brincam a vontade, não é a toa que meus filhos gostam de ir". Destaca que "mesmo sem receber o dinheiro, o PETI ajuda sim, bastante até, principalmente nessa parte que as crianças não estejam na rua".

Para a avó de Joana, a sua participação do PETI possibilitou que tivesse mais espaço de lazer, pois no programa começou a realizar diversas atividades como jogar bola e fazer outras atividades físicas. Ressalta que "criança sempre gosta de ter um lugar pra brincar, brinquedo é tudo". Conta, ainda, que a participação da Joana no projeto fez diferença para a família: "Pra família mudou porque se eu vou trabalhar eu sei que ela tá segura, porque pelo menos ela não tá ai na rua $[\ldots]$ e então a gente sabe que ela tá aprendendo alguma coisa, aprendendo muita coisa lá".

As entrevistas evidenciam a importância da existência da UASE na vida das crianças, adolescentes e suas famílias como espaço de convivência, sociabilidade, cuidado e segurança, produzindo transformações em seu cotidiano conforme as falas já destacadas no texto.

Herkenhoff \& Prates e Ministério do Desenvolvimento Social e Combate à Fome (2009) também constatou a importância do PETI, de acordo com a opinião de mães, na vida das famílias e de seus filhos. "O PETI traz mudanças nas suas vidas e de seus filhos e seus ganhos são significativos por saberem que os filhos estariam bem cuidados" ( $p .68$ ). A maioria das mães reconhece também "os ganhos advindos das atividades socioeducativas na vida de seus filhos" ( $p$. 68).

No entanto, ao considerar-se o objetivo do PETI, a pesquisa constata que as crianças, a adolescente e suas famílias não têm clareza que a frequência ao PETI/UASE, além de ser uma condição para o recebimento da Bolsa Família, tem por objetivo a erradicação das situações de trabalho infantil. Também não se identificou nenhuma ação do PETI/UASE ou do CRAS com as famílias das crianças e adolescentes ou o acompanhamento por parte das famílias às atividades do PETI.

Assim, pode-se analisar que a integração do PETI com o PBF, por meio das UASEs, possibilita a ampliação das atividades socioeducativas, permitindo a convivência entre crianças e adolescentes que vivenciam ou não a realidade de trabalho infantil, isto é, permite a interação entre realidades diversas, evitando 
estigmas identitários. Por outro lado, o enfrentamento da situação de trabalho infantil fica em segundo plano, o que pode contribuir para a continuidade de situações que deveriam ser superadas. Essa preocupação também está presente no estudo de Herkenhoff \& Prates e Ministério do Desenvolvimento Social e Combate à Fome (2009, p. 67) que ressalta o fato de que "a questão do trabalho infantil não parecia muito clara, e, para uma boa parcela de participantes [mães e/ou responsáveis], não seria necessariamente vista como algo negativo".

Rua (2007, p. 38-39), ao avaliar a integração do PETI ao PBF, destaca que há "falta de definição precisa e pactuada do conceito de trabalho infantil e de ações socioeducativas e de convivência", o que reduz a sustentabilidade das ações governamentais. Ressalta ainda a ausência da inclusão ocupacional das famílias beneficiárias e a perda dos incentivos à retirada das crianças/ adolescentes da situação de trabalho.

\section{Considerações finais}

A pesquisa analisou as implicações do Programa de Erradicação do Trabalho Infantil (PETI) no cotidiano de crianças, adolescentes que dele participam e suas famílias, com base em pesquisa realizada em duas unidades localizadas em Chapecó (SC) e acompanhamento de três crianças e uma adolescente e suas famílias. Os resultados indicam a importância do programa para as crianças e suas famílias no que diz respeito à possibilidade de participarem de um espaço, considerado seguro, com atividades que contribuem com 0 desenvolvimento social, afetivo e pedagógico.

No entanto, percebeu-se que a existência do PETI não garante a participação integral das crianças e adolescente em situação de trabalho infantil, pois estas deixam de frequentá-lo em momentos que precisam auxiliar seus responsáveis em tarefas no âmbito familiar. Assim, analisamos que a rede que vem sendo tecida pelo programa ainda não possibilita uma transformação efetiva no cotidiano das crianças e adolescentes que dela participam no que diz respeito à erradicação do trabalho infantil.

A utilização da TAR como dispositivo teórico-metodológico possibilitou dar visibilidade a cenas, relatos e versões e apreender a multiplicidade presente na realidade das famílias e na participação de crianças e adolescentes no PETI. Ainda permitiu ver que uma

rede não é algo já dado, ela se constrói e se mantém a partir dos vínculos que unem os actantes [atores]; para se manter estável ela necessita do trabalho cotidiano dos atores e da tradução permanente dos diferentes interesses. Elementos 
podem ser articulados e desarticulados, fluxos podem ser estabilizados e desestabilizados. (Bonamigo, 2008, p. 358).

A visibilidade das cenas e relatos cotidianos permitiu vislumbrar a importância do recebimento do benefício da Bolsa Família para a existência da rede (ou incentivos à retirada das crianças e adolescentes da situação de trabalho); também a necessidade da articulação de outros atores na rede para o seu fortalecimento, com a conexão de: programas de geração de trabalho e renda para as famílias e equipamentos públicos, como centros de educação infantil para crianças de zero a três anos e acesso de familiares a Centro de Atenção Psicossocial de Álcool e outras Drogas (CAPS AD), entre outros. Ainda, desafiou a pensar os vínculos que são ou não estabelecidos na rede na perspectiva de que, por exemplo, a escola, ao se articular com a UASE, possa se constituir como um ator da rede, produzindo outros efeitos no combate ao trabalho infantil. Vislumbra-se a necessidade da construção de uma rede, cujas conexões possibilitem aos pais ao mesmo tempo trabalhar, ter a casa cuidada e seus filhos protegidos, pois são essas as situações que levam à necessidade das crianças e a adolescentes trabalharem com prejuízo da frequência ao PETI e por vezes à escola. Percebe-se, assim, que a rede tecida pelo PETI tem voltado a atenção às crianças e adolescentes, não conseguindo possibilitar condições para que as famílias exerçam plenamente a sua função de proteção de seus filhos.

\section{Referências}

Andrade, J. A (2006). Redes de atores: uma nova forma de gestão das políticas públicas no Brasil. Gestão \& Regionalidade, 22(64), mai./ago., p. 52-66.

Arendt, R. (2007). Emoções e mídia. In A. Jacó-Vilela, \& L. Sato. (Orgs.). Diálogos em Psicologia Social (pp. 275-286). Porto Alegre: Editora Evangraf.

Arretche, M. (1998). Tendências no estudo sobre avaliação. In E. Rico (Org.). Avaliação de políticas: uma questão em debate (pp. 2939). São Paulo: Cortez Editora; IEE/PUC/SP.

Bonamigo, I. S. (2008). Tecendo relato, versões e cenas: etnografia de um evento violento. Psicologia \& Sociedade, 20(3), 350-359.

Fundação Euclides da Cunha; Ministério do Desenvolvimento Social e Combate à Fome (2009). Secretaria de Avaliação e Gestão da Informação. Departamento de Avaliação e Monitoramento. Pesquisa quantitativa de avaliação do Programa de Erradicação do Trabalho Infantil (PETI): sumário executivo. Brasília: MDS. Recuperado em 20 de maio, 2014, de 
http: //aplicacoes.mds.gov.br/sagi/PainelPEl/Publicacoes/Pesqui sa(PETI).pdf

Herkenhoff \& Prates, Ministério do Desenvolvimento Social e Combate à Fome (2009). Secretaria de Avaliação e Gestão da Informação. Departamento de Avaliação e Monitoramento. Pesquisa qualitativa para avaliação do Programa de Erradicação do Trabalho Infantil (PETI): sumário executivo. Brasília: MDS. Recuperado em 20 de maio, 2014, de http://aplicacoes.mds.gov.br/sagi/PainelPEI/Publicacoes/PETI20 Quali dezembro 2009.pdf

Herkenhoff ${ }^{-} \&$ Prates, Ministério do Desenvolvimento Social e Combate à Fome (2010). Estudo qualitativo para a avaliação do Programa de Erradicação do Trabalho Infantil. Cadernos de Estudos Desenvolvimento social em debate. Síntese das pesquisas de avaliação de programas sociais do MDS (2006 2010). 64-69. Brasília, Ministério de Desenvolvimento Social e Combate à Fome.

Latour, B. (2001). A esperança de Pandora. Bauru: EDUSC.

Latour, B. (2006). Changer de société. Refaire de la sociologie. Paris: La Découverte.

Latour, B. (2012). Reagregando o social: uma introdução à Teoria do Ator-Rede. Salvador: Edufba; Bauru, São Paulo: Edusc.

Brasil (1993). Lei no 8.742, de 7 de dezembro de 1993. Dispõe sobre a organização da Assistência Social e dá outras providências. Diário Oficial da União de 8/12/1993. Recuperado em 10 de abril, 2014, de http://www.planalto.gov.br/ccivil_03/leis/L8742.htm

Medeiros Neto, X. T., \& Marques, R. D. (2013). Manual de Atuação do Ministério Público na Prevenção e Erradicação do Trabalho Infantil. Conselho Nacional do Ministério Público. - Brasília: CNMP.

Ministério do Desenvolvimento Social e Combate à Fome (2010a). Secretaria Nacional de Assistência Social. LOAS anotada: Lei Orgânica da Assistência Social. MDS: Brasília, 2009. Recuperado em 10 de abril, 2014, de http://www.mds.gov.br/assistenciasocial/secretaria-nacionalde-assistencia-social-snas/cadernos/lei-organica-de-assistenciasocial-loas-anotada-

2009/Lei\% 20Organica\% 20de\% 20Assistencia\% 20Social\% 20 -

\% 20LOAS\% 20Anotada\% 202009.pdf/download

Ministério do Desenvolvimento Social e Combate à Fome (2010b). Secretaria Nacional de Assistência Social. Departamento de Proteção Social Especial. Caderno de orientações técnicas: gestão do Programa de Erradicação do Trabalho Infantil no SUAS. Brasília: MDS. 
Rua, M.G. (2007). Avaliação da integração do programa de erradicação do trabalho infantil (PETI) ao programa bolsafamília (PBF). Brasília, Fórum Nacional de Prevenção e Erradicação do Trabalho Infantil.

\section{Endereço para correspondência \\ I rme Salete Bonamigo}

Universidade Comunitária Regional de Chapecó - Unochapecó

Av. Senador Atílio Fontana, 591-E, EFAPI, CEP 89809-000, Chapecó - SC, Brasil

Endereço eletrônico: bonamigo@unochapeco.edu.br

\section{Celso Francisco Tondin}

Universidade Comunitária da Região de Chapecó - Unochapecó

Av. Senador Atílio Fontana, 591-E, EFAPI, CEP 89809-000, Chapecó - SC, Brasil

Endereço eletrônico: tondin@unochapeco.edu.br

\section{Misael Szytko}

Universidade Comunitária da Região de Chapecó - Unochapecó

Av. Senador Atílio Fontana, 591-E, EFAPI, CEP 89809-000, Chapecó - SC, Brasil

Endereço eletrônico: m.szytko@unochapeco.edu.br

\section{Eduarda Moro}

Universidade Comunitária da Região de Chapecó - Unochapecó

Av. Senador Atílio Fontana, 591-E, EFAPI, CEP 89809-000, Chapecó - SC, Brasil

Endereço eletrônico: eduaradamoro@unochapeco.edu.br

\section{Tiago Ramos}

Universidade Comunitária da Região de Chapecó - Unochapecó

Av. Senador Atílio Fontana, 591-E, EFAPI, CEP 89809-000, Chapecó - SC, Brasil

Endereço eletrônico: dops_tiago@unochapeco.edu.br

\section{Giovane Biazi}

Universidade Comunitária da Região de Chapecó - Unochapecó

Av. Senador Atílio Fontana, 591-E, EFAPI, CEP 89809-000, Chapecó - SC, Brasil

Endereço eletrônico: giovanebiazzi@unochapeco.edu.br

Recebido em: 31/05/2014

Aceito para publicação em: 22/09/2014

\section{Notas}

* Docente do Mestrado em Políticas Sociais e Dinâmicas Regionais e do Curso de Psicologia da Universidade Comunitária da Região de Chapecó, (Unochapecó), Chapecó, SC - Brasil. Doutora em Psicologia Social pela Universidade do Estado do Rio de J aneiro (UERJ)

** Docente do Mestrado em Educação e do Curso de Psicologia da Unochapecó, Chapecó, SC - Brasil. Doutor em Psicologia pela Pontifícia Universidade Católica do Rio Grande do Sul (PUCRS)

*** Estudante do Curso de Psicologia da Unochapecó, Chapecó (SC), Brasil

**** Estudante do Curso de Psicologia da Unochapecó, Chapecó (SC), Brasil

***** Mestre em políticas sociais e dinâmicas regionais pela Unochapecó, Chapecó, SC - Brasil

****** Estudante do Curso de Psicologia da Unochapecó, Chapecó (SC), Brasil. 